www.nature.com/clinicalpractice/endmet

\title{
Advances in the diagnosis and management of hyperinsulinemic hypoglycemia
}

\section{Ritika R Kapoor, Chela James and Khalid Hussain*}

Nature Clinical Practice Endocrinology \& Metabolism (2009) 5: 101-112 [doi:10.1038/ncpendmet1046]

doi:10.1038/ncpendmet1096

In the February 2009 print issue, due to a technical error, all incidences of the letter 1 in small capitals in this article incorrectly appeared as the letter $\mathrm{k}$. This erratum applies to the print issue only; the full text version and the PDF online are correct.

\section{Early insulin therapy does not improve survival in babies with very low birth weight}

Nature Clinical Practice Endocrinology \& Metabolism (2009) 5: 64 [doi:10.1038/ncpendmet1028]

doi:10.1038/ncpendmet1104

\section{ERRATUM}

In the February 2009 issue, the final sentence of this Research Highlight should have read "The authors conclude that elective use of early insulin therapy in newborn babies who weigh $<1.5 \mathrm{~kg}$ does not improve survival, and is associated with an increased risk of hypoglycemia in those $>1 \mathrm{~kg}$ in weight." 